\title{
Yields in biomass and chemical constituents of four commercially important marine microalgae with different culture media
}

Concepcion Herrero, Angeles Cid

Laboratorio de Microbiologia, Departamento de Biologia Celulary Molecular, Universidad de la Coruña, 15071 La Coruna, Spain

Jaime Fabregas, Julio Abalde

Laboratorio de Microbiologia, Facultad de Farmacia, Universidad de Santiago, 15771, Santiago de Compostela, Spain

\section{Aquacultural Engineering}

Volume 10, Issue 2, 1991, Pages 99-110

Received 20 July 1990, Accepted 13 February 1991, Available online 1 October 2003

doi: 10.1016/0144-8609(91)90003-3

\section{Abstract}

The use of the commercial nutrient Algal-1 was studied in mass cultures of the marine microalgaeTetraselmis suecica, Dunaliella tertiolecta, Isochrysis galbana and Phaeodactylum tricornutum, in comparison with the use of media such as ES-Provasoli, and Walne medium.

Maximum cell concentrations were always found in Algal-1 cultures and these values were always significantly higher than those obtained in the remaining media. The cellular density obtained in Algal-1 cultures was between $59 \%$ and $79 \%$ higher than that obtained in the traditional culture media used for T. suecica, between $70 \%$ and 
$109 \%$ for D. tertiolecta, between $33 \%$ and $60 \%$ for $I$. galbana and between $63 \%$ and $105 \%$ for $P$. tricornutum.

The culture medium used affected the chemical composition of microalgal cells. Protein is the major cellular component for all the sepcies assayed and with all the media proved. Maximum values of protein/cell were obtained in Algal-1 cultures, except for $P$. tricornutum, whereas maximum values of reserve products (carbohydrates and lipids) never occurred in Algal-1 cultures, except for $T$. suecica. Differences in the protein content were higher than those found in the other cellular constituents.

Maximum values of protein, lipids and carbohydrates per liter of culture always occurred in Algal-1 cultures, with significant differences in the values obtained in the remaining cultures. Maximum protein concentration (mg/liter) obtained in Algal-1 cultures was between $155 \%$ and $334 \%$ higher than that obtained in the remaining media for $T$. suecica, between $75 \%$ and $194 \%$ for $D$. tertiolecta, between $75 \%$ and $195 \%$ for $I$. galbana and between $93 \%$ and $225 \%$ for $P$. tricornutum. Daily protein yields (mg liter/day) also occurred in Algal-1 cultures.

Ratios between protein values per liter of culture reached in each traditional medium and those reached in Algal-1 show values between 0.2 and 0.6 for protein content; therefore, Algal-1 cultures produced between 2 and 5 times more protein than the remaining cultures. Ratios for carbohydrates and lipids were between 0.4 and 1.0 , and differences between traditional culture media and Algal-1 were generally lower than those obtained for proteins.

Results showed better yields in Algal-1 cultures than those obtained with these traditional culture media.

\section{Indexed keywords}

Engineering controlled terms: Algae - Agricultural Applications; Biomass - Production; Carbohydrates - Biosynthesis; Lipids - Biosynthesis; Proteins - Biosynthesis

Engineering uncontrolled terms: Algae Culture; Marine Microalgae

Engineering main heading: Aquaculture

Species Index: algae; Dunaliella tertiolecta; Isochrysis galbana; Phaeodactylum tricornutum; Tetraselmis suecica 


\section{Introduction}

The cultivation of microalgae is part of the biotechnology of growing marine molluscs, crustaceans and fishes. In all types of molluscan aquaculture it is necessary to have a large microalgal biomass available as a source of food for normal development and growth of the cultured species. In fact, production of this biomass is frequently cited as critical to the success of the project and as being a serious impediment to the future development to shellfish aquaculture (De Pauw et al., 1983). The mass culture of certain species of microalgae is considered the major bottleneck in the nursery culturing of molluscs (Persoone \& Claus, 1980).

Mass production of microalgae has long been successfully carried out either by using domestic or industrial wastes (De La Noue \& De Pauw, 1988; Oswald, 1988) or inorganic compounds, although in rearing of marine molluscs clean nutrient sources are often used (Shelef \& Soeder, 1980; Fabregas et al., 1985). These media are generally laboratory preparations, with a relatively high economic cost (Stein, 1973; Soeder, 1980; Fabregas et al., 1984; Fabregas et al., 1985). Different efforts have been carried out for using common fertilizers as microalgal nutrients (GonzalezRodriguez \& Maestrini, 1984; Fabregas et al., 1987), but results were not as good as those obtained with the different synthetic algal nutrients (Stein, 1973; GonzalezRodriguez \& Maestrini, 1984). Recently, a commercial nutrient for marine microalgae (Algal-1) has been developed by Nutricion Avanzada SA, Santiago de Compostela, Spain.

The use of this commercial nutrient Algal- 1 was studied in mass cultures of the marine microalgae Tetraselmis suecica, Dunaliella tertiolecta, Isochrysis galbana and Phaeodactylum tricornutum, in comparison with the use of media such as ESProvasoli, $\mathrm{f} / 2$ and Walne medium.

\section{Material and methods}

Four different marine microalgae were used: Tetraselmis suecica, Dunaliella tertiolecta, Isochrysis galbana and Phaeodactylum tricornutrum var. bicornutum. They were cultured in seawater filtered through a $0.45 \mu \mathrm{rn}$ Millipore filter, autoclaved at $120^{\circ} \mathrm{C}$ for $20 \mathrm{~min}$ and enriched with the different culture media: ES-Provasoli, f/2 and Walne (Stein, 1973; Walne, 1974) and Algal-I. This medium was prepared following the manufacturer instructions. 
Mass cultures were carried out in a controlled environmental incubator at $18 \pm 1^{\circ} \mathrm{C}, 130$ $\mu \mathrm{Em} / \mathrm{s}$ light from fluorescent lamps and $35 \%$ o salinity. A $12: 12$ light-dark period was maintained. Cultures had air continuously bubbled through them at a rate of 15 liters $/ \mathrm{min}$. The inocula used were: $0.5 \times 10^{6} \mathrm{cells} / \mathrm{ml}$ for $T$. suecica cultures, $0.75 \times 10^{6}$ cells $/ \mathrm{ml}$ for $D$. tertiolecta cultures, $2.5 \times 10^{6} \mathrm{cells} / \mathrm{ml}$ for I galbana cultures and $1.5 \times 10^{6}$ cells $/ \mathrm{ml}$ for $P$. tricornutum cultures.

Microalgal growth was determined daily by counting culture aliquots in a Coulter Counter model DN.

To obtain growth, velocity doublings/day were calculated: doublings/day $=\frac{\ln N(n)-\ln N(i)}{\ln 2\left(t_{n}-t_{i}\right)}$

where $t$; and $t_{n}$ are the initial and final time of the logarithmic phase, both expressed in days, and $N(i)$ and $N(n)$ are the initial and final cellular densities, respectively.

Protein and carbohydrates were measured in the crude extract obtained after collecting the microalgal cells by centrifugation, resuspending them in distilled water and breaking them in an ultrasonic disintegrator. After sonication for $5 \mathrm{~min}$, the extracts were centrifuged again, the pellets were discarded and protein and carbohydrates were measured in the supernatants. Protein was measured by the dye-binding method (Bradford, 1976) and carbohydrates by the phenol-sulfuric acid method as described by Kochert (1978).

Lipids were measured by the charring method of Marsh and Weistein (1966).

Stationary phases, corresponding to maximum biomass production, were compared by an overall multivariate one-way analysis of variance (ANOVA) $(P \leq 0.05)$.

\section{Results and discussion}

The marine microalgal species assayed grew in all the culture media used but growth was significantly higher in Algal-I cultures than in the remaining culture media used, for all the microalgal species assayed (Fig. 1). It is well known that the growth of microalgae in batch cultures is often well characterized by the logistic growth function. The growth kinetics model of all the cultures carried out in the present experiments (Fig. 1) fitted a logistic curve (Schanz \& Zahler, 1981). 


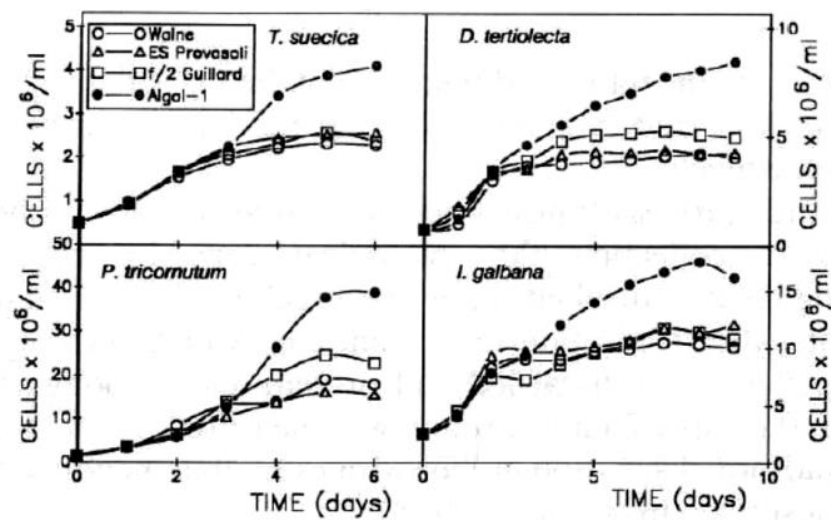

Fig. 1. Growth curve of different marine microalgae grown with different culture media.

The culture medium used affected- the velocity of growth of the cultures of the different marine microalgae, but this effect was lower than their effect on biomass production at the end of the stationary phase. Maximum growth rates in the logarithmic phase were between 0.91 and 0.95 doublings/day for $T$. suecica, between 1.04 and 1.58 doublings/day for $D$. tertiolecta, between 0.85 and 1.16 doublings/day for I. galbana and between 1.13 and 1.32 doublings/day for $P$. tricornutum. As previously shown, variations in different parameters such as salinity, nutrient concentration or nutrient composition had a greater effect on the final biomass of different microalgal species than on the velocity of growth (Fabregas et al., 1984, 1985).

Maximum cellular densities at the stationary phase were always found in Algal-1 cultures (Fig. 2, Table 1), and these values were always significantly higher than those obtained in the remaining media. These maximum cellular densities were $4.11 \times 10^{6}$ cells $/ \mathrm{ml}$ for $T$. suecica, $8.45 \times 10^{6}$ cells $/ \mathrm{ml}$ for $D$. tertiolecta, $16.15 \times 10^{6}$ cells $/ \mathrm{ml}$ for $I$. galbana and $39.04 \times 10^{6}$ cells $/ \mathrm{ml}$ for $P$. tricornutum. Cellular densities obtained with the remaining culture media were very similar for $T$. suecica, D. tertiolecta and I. galbana, with differences ranging between $13 \%$ and $23 \%$. However, these variations are higher in $P$. tricornutum cultures, with $\mathrm{f} / 2$ cultures showing cellular densities $30 \%$ and $52 \%$ higher than those obtained in Walne and ES Provasoli media, respectively, although the cellular density reached in $\mathrm{f} / 2$ medium only accounted for $58 \%$ of that reached in the Algal-1 medium.

Considering the ratio between the maximum cellular density reached in each traditional medium and maximum cellular density reached in Algal-1 for all the species studied (Table 2), ratios near to 0.5 occurred for Tetraselmis suecica, Dunaliella tertiolecta and Phaeodactylum tricornutum, whereas higher ratios appear in Isochrysis galbana cultures. Therefore, microalgal yields can be doubled by using algal medium instead of Walne, $\mathrm{f} / 2$ or ES-Provasoli media. 


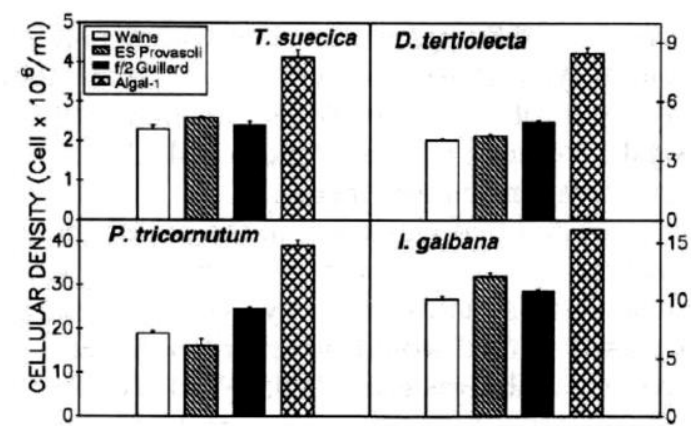

Fig. 2. Maximum cellular density (cells $\times 10^{6} / \mathrm{ml}$ ) in the stationary phases of marine microalgae grown with different culture media.

The culture medium used affected the biochemical composition of microalgal cells (Table 1). Protein is the major cellular component for all the species assayed and with all the media proved. Differences in the protein content were higher than those found in the other cellular constituents. Protein/cell ratios obtained in the different traditional culture media were, in all cases, significantly $(P<0.05)$ different to those obtained in the AJgal-1 medium, for all the species assayed (Table 1).

TABLE 1

Cellular Density $\left(\right.$ Cells $\left.\left.\times 10^{6}\right) / \mathrm{ml}\right)$ and Chemical Compmosition $(\mathrm{pg} / \mathrm{Cell})$ of Four Marine Microalgae Grown in Different Culture Media

\begin{tabular}{lcccc}
\hline & Cellular density & Protein & Carbohydrates & Lipids \\
\hline T. suecica & & & & \\
Walne & $2 \cdot 29$ & $13 \cdot 31$ & $6 \cdot 20$ & $7 \cdot 04$ \\
ES & $2 \cdot 58$ & $16 \cdot 98$ & $6 \cdot 93$ & $7 \cdot 22$ \\
f/2 & $2 \cdot 38$ & $21 \cdot 75$ & $8 \cdot 37$ & $7 \cdot 92$ \\
Algal-1 & $4 \cdot 11$ & $32 \cdot 22$ & $8 \cdot 83$ & $8 \cdot 65$ \\
D. tertiolecta & & & & \\
Walne & $4 \cdot 04$ & $13 \cdot 37$ & $13 \cdot 22^{a}$ & $22 \cdot 28$ \\
ES & $4 \cdot 24$ & $14 \cdot 88$ & $15 \cdot 73$ & $23 \cdot 94$ \\
f/2 & $4 \cdot 97$ & $13 \cdot 26$ & $17 \cdot 91$ & $23 \cdot 67$ \\
Algal-1 & $8 \cdot 45$ & $18 \cdot 82$ & $11 \cdot 08$ & $18 \cdot 18$ \\
I. galbana & & $*$ & & \\
Walne & $10 \cdot 11$ & $5 \cdot 17$ & $4 \cdot 28^{a}$ & $25 \cdot 95$ \\
ES & $12 \cdot 09$ & $7 \cdot 23$ & $5 \cdot 21$ & $28 \cdot 38$ \\
f/2 & $10 \cdot 81$ & $8 \cdot 13$ & $5 \cdot 59$ & 26.82 \\
Algal-1 & $16 \cdot 15$ & $9 \cdot 57$ & $4 \cdot 28$ & $20 \cdot 68$ \\
P. tricornutum & & & & \\
Walne & $19 \cdot 01$ & $2 \cdot 65$ & $6 \cdot 42^{a}$ & $6 \cdot 51$ \\
ES & $16 \cdot 23$ & $5 \cdot 21$ & $9 \cdot 20$ & $6 \cdot 45$ \\
f/2 & $24 \cdot 65$ & $3 \cdot 34$ & $6 \cdot 90$ & $5 \cdot 52$ \\
Algal-1 & $39 \cdot 04$ & $4 \cdot 20$ & $5 \cdot 98$ & $5 \cdot 79$ \\
\hline
\end{tabular}

${ }^{a}$ Not significantly different of Algal-1 cultures.

Maximum values of protein: cell were obtained in Algal-1 cultures, except for $P$. tricornutum cultures. These maximum values were $32.22 \mathrm{pg} / \mathrm{cell}$ for $T$. suecica, 18.82 $\mathrm{pg} /$ cell for $D$. tertiolecta and $9.57 \mathrm{pg} /$ cell for $I$. galbana. Contrarily, in $P$. tricornutum cultures, maximum protein/cell concentrations were obtained in Walne medium with 
$5.21 \mathrm{pg} / \mathrm{cell}$. Therefore, Algal-I cultures produced more cells (Fig. 2) that had more protein than the remaining culture media.

TABLE 2

Ratios Between Values of Cellular Density, Protein/liter Carbohydrates/liter and Lipids/ liter Obtained in Each Medium and Those Obtained in Algal-1 Medium

\begin{tabular}{lcccc}
\hline & Cellular density & Protein & Carbohydrates & Lipids \\
\hline T. suecica & & & & \\
Walne & 0.55 & 0.23 & 0.39 & 0.45 \\
ES & 0.62 & 0.33 & 0.49 & 0.52 \\
f/2 & 0.57 & 0.39 & 0.55 & 0.53 \\
Algal-1 & 1.00 & 1.00 & 1.00 & 1.00 \\
D. tertiolecta & & & & \\
Walne & 0.47 & 0.34 & 0.56 & 0.58 \\
ES & 0.50 & 0.40 & 0.69 & 0.66 \\
f/2 & 0.58 & 0.41 & 0.93 & 0.76 \\
Algal-1 & 1.00 & 1.00 & 1.00 & 1.00 \\
I. galbana & & & & \\
Walne & 0.62 & 0.34 & 0.63 & 0.79 \\
ES & 0.74 & 0.56 & 0.91 & 1.03 \\
f/2 & 0.67 & 0.57 & 0.88 & 0.87 \\
Algal-1 & 1.00 & 1.00 & 1.00 & 1.00 \\
P. tricornutum & & & & \\
Walne & 0.48 & 0.31 & 0.52 & 0.55 \\
ES & 0.41 & 0.52 & 0.64 & 0.46 \\
f/2 & 0.63 & 0.50 & 0.73 & 0.60 \\
Algal-1 & 1.00 & 1.00 & 1.00 & 1.00
\end{tabular}

It has been suggested that variability in the protein content per cell is the most important factor in the use of marine microalgae for animal feeding in aquaculture systems, and any system of mariculture where microalgae are used as feed would be severily affected by variations in their protein content (Fabregas et al., 1985; Wikfors, 1986).

However, maximum values of reserve products (carbohydrates and lipids) never occurred in Algal-I cultures, except for $T$. suecica (Table 1). Maximum carbohydrates/cell values occurred in Algal-1 for $T$. suecica with $8.83 \mathrm{pg} / \mathrm{cell} ; \mathrm{f} / 2$ cultures for $D$. tertiolecta and I. galbana, showed 17.91 and $5.59 \mathrm{pg} /$ cell, respectively, and Walne medium for $P$. tricornutum showed $9.20 \mathrm{pg} / \mathrm{cell}$.

Lipids constitute the most constant cellular fraction for all the species in the different culture media (Table 1). Values were between 7.04 and $8.65 \mathrm{pg} / \mathrm{cell}$ for $T$. suecica, between 18.18 and $23.94 \mathrm{pg} /$ cell for $D$. tertiolecta, between 20.68 and $28.38 \mathrm{pg} / \mathrm{cell}$ for I. galbana and between 5.52 and 6.45 for $P$. tricornutum.

Differences in cellular densities and cellular contents provoked higher variations in the values of protein, lipids and carbohydrates obtained per liter of culture. 
Maximum values of protein, lipids and carbohydrates per liter of culture always occurred in Algal-I cultures, with significant differences in the values obtained in the remaining cultures (Figs 3-6). Maximum protein concentrations in $\mathrm{mg} / \mathrm{liter}$ of culture were $132.43 \mathrm{mg} /$ liter for $T$. suecica, $159.04 \mathrm{mg} /$ liter for $D$. tertiolecta, $154.5 \mathrm{for} \mathrm{I}$. galbana and 163.88 for P. tricornutum, always in Algal-I cultures (Figs 3-6).

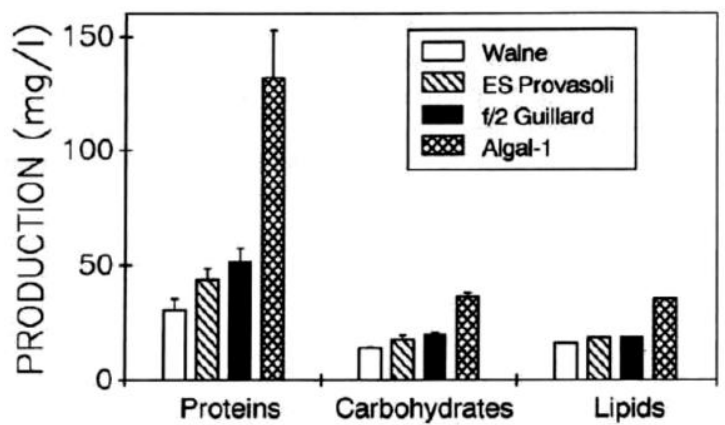

Fig. 3. Maximum protein, lipids and carbohydrates values ( $\mathrm{mg} / \mathrm{liter}$ ) obtained in cultures of the marine microalga Tetraselmis suecica grown in different culture media.

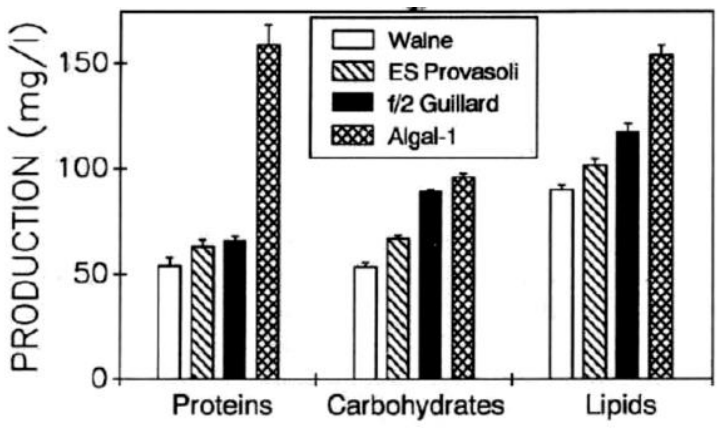

Fig. 4. Maximum protein, lipids and carbohydrates values (mg/liter) obtained in cultures of the marine microalga Dunaliella tertiolecta grown with different culture media.

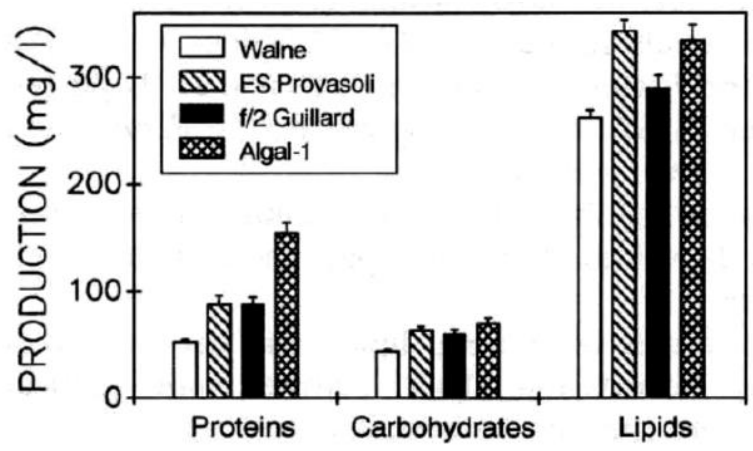

Fig. 5. Maximum protein, lipids and carbohyhdrates values (mg/liter) obtained in cultures of the marine microalga Isochrvsis salbana grown with different culture media. 


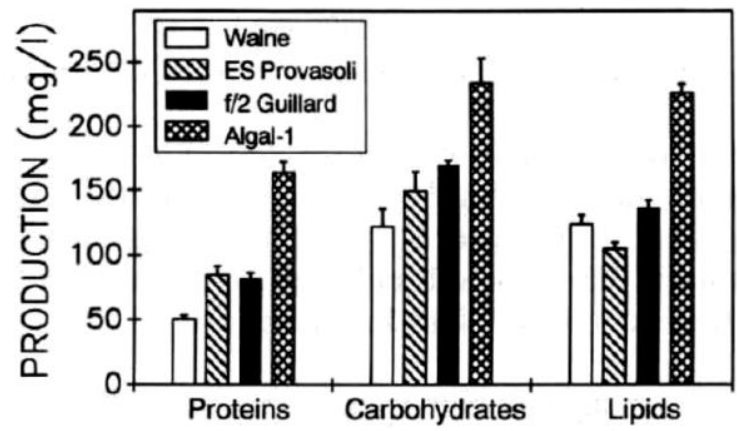

Fig. 6. Maximum protein, lipids and carbohydrates values (mg/liter) obtained in cultures of the marine microalga Phaedactylum tricornutum grown with different culture media.

Maximum carbohydrates/liter concentrations also occurred in Algal-1 cultures (Figs 36) with values of $36.31 \mathrm{mg} / \mathrm{liter}$ for $T$ suecica, $95.75 \mathrm{mg} /$ liter for $D$. tertiolecta, $69 \cdot 18$ $\mathrm{mg} /$ liter for $I$. galbana and $233.56 \mathrm{mg} /$ liter for $P$. tricornutum. Maximum lipids concentration per liter of culture occurred in Algal-1 cultures for $T$ suecica, $D$. tertiolecta and $P$. tricornutum, with values of $35.55 \mathrm{mg} / \mathrm{liter}, 153.66 \mathrm{mg} / \mathrm{liter}$ and $225.86 \mathrm{mg} / \mathrm{liter}$, respectively, whereas in $I$. galbana cultures maximum lipid concentration per liter occurred in ES Provasoli medium (343'12 mg/liter). Variations in carbohydrate and lipid concentrations per liter of culture are lower than those found in protein/liter for all the species assayed (Figs 3-6).

Ratios between protein, carbohydrate and lipid values per liter of culture reached in each traditional medium and those reached in Algal-1 were calculated for all the species studied (Table 2). Ratios between 0.2 and 0.6 were found for protein content; therefore, Algal-1 cultures produced between 2 and 5 times more protein than the remaining cultures. Ratios for carbohydrates and lipids were between 0.4 and 1,0, and differences between traditional culture media and Algal-I were generally lower than those obtained for proteins.

Biomass yields, as number of cells per $\mathrm{ml}$ of culture per day, were always maximum in Algal-I cultures (Table 1), showing significantly higher values than those obtained in the remaining culture media. These maximum biomass yields were $60 \times 10^{4} \mathrm{cells} / \mathrm{ml} / \mathrm{day}$ for $T$ suecica, $86 \times 10^{4}$ cells $/ \mathrm{ml} /$ day for $D$. tertiolecta, $152 \times 10^{4} \mathrm{cells} / \mathrm{ml} /$ day for $I$. galbana and $626 \times 10^{4}$ cells $/ \mathrm{ml} /$ day for $P$. tricornutum. These values are between $71 \%$ and $100 \%$ higher than those obtained in the remaining cultures for T. suecica, between $83 \%$ and $132 \%$ for D. tertiolecta, between $42 \%$ and $79 \%$ for I. galbana and between $62 \%$ and $154 \%$ for $P$. tricornutum.

Maximum yields in protein, carbohydrate and lipid per liter of culture per day were obtained in Algal-1 cultures for all the species assayed, excepting the yield in lipids for 
I. galbana cultures, which reached the maximum value in ES-Provasoli cultures (31-33 $\mathrm{mg} /$ liter/day) without significant differences from Algal-1 cultures (30-30 mg/liter/day) (Table 3)_

Yields in protein showed higher differences than those found both in carbohydrates and lipids (Table 2)_ Daily protein yields in Algal-1 medium were $20-10 \mathrm{mg} / \mathrm{liter} /$ day for $T$. suecica cultures, $15-66 \mathrm{mg} / \mathrm{liter} /$ day for $D$. tertiolecta, $14-90 \mathrm{mg} / \mathrm{liter} /$ day for $I$. galbana and $26-06 \mathrm{mg} /$ liter/day for $P$. tricornutum, whereas daily protein yields with the traditional culture media used were between 3-10 and 6-65 mg/liter/day for $T$. suecica cultures, between 3-99 and 5-32 mg/liter/day for D. tertiolecta cultures, between 3.54 and $7.49 \mathrm{mg} /$ liter/day for I. galbana and between $7-42$ and $12.73 \mathrm{mg} /$ liter/day for $P$. tricornutum cultures.

TABLE 3

Yields in Cells (Cells $\times 10^{6} /$ per ml/day), Protein, Carbohydrates and Lipids (mg/liter/ day) of Four Marine Microalgae Grown in Different Culture Media

\begin{tabular}{|c|c|c|c|c|}
\hline & Cellular density & Protein & Carbohydrates & Lipids \\
\hline \multicolumn{5}{|l|}{ T. suecica } \\
\hline Walne & $0 \cdot 30$ & $3 \cdot 10$ & 1.58 & $1 \cdot 30$ \\
\hline ES & $0 \cdot 35$ & $5 \cdot 33$ & $2 \cdot 19$ & 1.72 \\
\hline$f / 2$ & $0 \cdot 31$ & $6 \cdot 65$ & 2.53 & 1.75 \\
\hline Algal-1 & $0 \cdot 60$ & $20 \cdot 10$ & $5 \cdot 26$ & $4 \cdot 54$ \\
\hline \multicolumn{5}{|c|}{ D. tertiolecta } \\
\hline Walne & $0 \cdot 37$ & 3.99 & $5 \cdot 01$ & 8.51 \\
\hline ES & $0 \cdot 39$ & 5.00 & $6 \cdot 49$ & $9 \cdot 79$ \\
\hline$f / 2$ & $0 \cdot 47$ & $5 \cdot 32$ & 8.97 & 11.58 \\
\hline Algal-1 & $0 \cdot 86$ & $15 \cdot 66$ & $9 \cdot 72$ & $15 \cdot 58$ \\
\hline \multicolumn{5}{|l|}{ I. galbana } \\
\hline Walne & $0 \cdot 85$ & 3.54 & $2 \cdot 68$ & $22 \cdot 35$ \\
\hline ES & 1.07 & $7 \cdot 44$ & $4 \cdot 88$ & $31 \cdot 33$ \\
\hline$f / 2$ & $0 \cdot 92$ & $7 \cdot 49$ & 4.59 & $25 \cdot 42$ \\
\hline Algal-1 & 1.52 & 14.90 & $5 \cdot 56$ & $30 \cdot 30$ \\
\hline \multicolumn{5}{|c|}{ P. tricornutum } \\
\hline Walne & 2.92 & $7 \cdot 42$ & $18 \cdot 30$ & $19 \cdot 37$ \\
\hline ES & $2 \cdot 46$ & $13 \cdot 13$ & $22 \cdot 86$ & $16 \cdot 19$ \\
\hline $\mathrm{f} / 2$ & 3.86 & $12 \cdot 73$ & $26 \cdot 32$ & $21 \cdot 43$ \\
\hline Algal-1 & $6 \cdot 26$ & 26.06 & 36.89 & $36 \cdot 39$ \\
\hline
\end{tabular}

Yields in carbohydrates varied between 1.58 and $5.26 \mathrm{mg} /$ liter/day in $T$. suecica cultures, between 5.01 and $9.72 \mathrm{mg} /$ liter/day for $D$. tertiolecta, between 2.68 and 5.56 $\mathrm{mg} /$ liter/day for I. galbana, and between 18.30 and $36.89 \mathrm{mg} / \mathrm{liter} / \mathrm{day}$ for $P$. tricornutum. Minimum yields in carbohydrates were obtained, for all the species assayed, in Walne cultures, which were about 50\% lower than those obtained in Algal1 cultures (Table 3).

With regards to lipids, the yields varied between 1.30 and $4.54 \mathrm{mg} / \mathrm{liter} / \mathrm{day}$ in $T$. suecica cultures, between 8.51 and $15.58 \mathrm{mg} /$ liter/day for $D$. tertiolecta, between 22.35 and $31.33 \mathrm{mg} / \mathrm{liter} /$ day for I. galbana, and between 16.19 and $36.39 \mathrm{mg} /$ liter/day for $P$. tricornutum (Table 2). 
In mariculture it has already been proved that differences in growth media affect the growth and gross chemical composition of algal food sources (Myklestad \& Haug, 1972; Shifrin \& Chisholm, 1980; Fabregas et al., 1985, 1986a, b), which alone can account for differences in algal nutritional value to commercially important marine herbivore species (Wikfors,1986).

ES-Provasoli, $\mathrm{f} / 2$ and Walne media are widely used in marine microalgae mass culture. Results showed better yields in Algal-1 cultures than yields obtained with these traditional culture media. Algal-1 was found to be a cheap nutrient supply and shows great feasibility for the preparation of microalgal culture media.

\section{Acknowledgements}

This work has been supported by a grant from Conselleria de Educacion, Xunta de Galicia (D.O.G. 16-12-87).

\section{References}

Bradford, M. (1976). A rapid and sensitive method for the quantitation of microgram quantities of protein utilizing the principle of protein-dye binding. Anal. Biochem., 72, 248-54.

De La Noue, J. \& De Pauw, N. (1988). The potential of microalgal biotechnology: a review of production and uses of microalgae. Biotech Adv., 6, 725-70.

De Pauw, N., Verboven, J. \& Claus, C. (1983). Large-scale microalgae production for nursery rearing of marine bivalves. Aquacultural Eng., 2, 27-47.

Fabregas, J., Abalde, J., Herrero, c., Cabezas, B. \& Veiga, M. (1984). Growth of the marine microalga Tetraselmis suecica in batch cultures with different salinities and nutrient concentrations. Aquaculture, 42, 207-15.

Fabregas, J., Herrero, C., Cabezas, B. \& Abalde, J. (1985). Mass culture and biochemical variability of the marine microalga Tetraselmis sueciea (Kylin) Butch with high nutrient concentrations. Aquaculture, 49, 231-44.

Fabregas, J., Herrero, C., Cabezas, B. \& Abalde, J. (1986a). Biomass production and biochemical composition in mass cultures of the marine microalga Isochrysis galbana Parke at varying nutrient concentrations. Aquaculture, 53, 101-13. 
Fabregas, J., Herrero, c., Abalde, J., Liaiio, R. \& Cabezas, B. (1986b). Biomass 'production and biochemical variability of the marine microalga Dunaliella tertiolecta (Butcher) with high nutrient concentrations. Aquaculture, 53, 187-99.

Fabregas, J., Toribio, L., Abalde, J., Cabezas, B. \& Herrero, C. (1987). Approach to biomass production of the marine microalga Tetraselmis suecica (Kylin) Butch using common garden fertilizer and soil extract as cheap nutrient supply in batch cultures. Aquacultural Engineering, 6,141-50.

Gonzalez-Rodriguez, E. \& Maestrini, S. Y. (1984). The use of some agricultural fertilizers for the mass production of mari/.le algae. Aquaculture, 36, 245-56.

Kochert, G. (1978). Carbohydrate determination by the phenol-sulfuric acid method. In Handbook of Phycological Methods. Physiological and Biochemical Methods, ed. J. A. Hellebust \& J. S. Craigie. Cambridge, pp. 95-7.

Marsh, J. B. \& Weinstein, D. B. (1966). Simple charring method for determinationoflipids. I. Lipid Res., 7, 574-6.

Myklestad, S. \& Haug, A. (1972). Production of carbohydrates by the marine diatom Chaetoceros a!finis var. willei (Gran) Hustedt. I. Effect of concentration of nutrients in the culture medium. 1. Exp. Mar. Biol. Eco!. , 9, 125-36.

Oswald, W. J. (1988 ). Micro-algae and waste-water treatment. In Microalgal Biotechnology, ed. M. A. Borowitzka \& L. J. Borowitzka. Cambridge, pp. 305-28.

Persoone, G. \& Claus, C. (1980). Mass culture of algae: a bottleneck in the nursery culturing of molluscs. In Algae Biomass. Production and Use, ed. G. Shelef \& c. J. Soeder. Elsevier/North Holland Biomedical Press, Amsterdam, pp. 265-85.

Schanz, F. \& Zahler, U. (1981). Prediction of algal growth in batch cultures. Schweiz. Z. Hydrol., $43(1), 103-13$.

Shelef, G. \& Soeder, C. J. (ed.) (1980 ). Algae Biomass. Production and Use. Elsevier/North Holland Biomedical Press, Amsterdam.

Shifrin, N. H. \& Chisholm, S. W. (1980). Phytoplankton lipids: environmental influences on production and possible commercial applications. In Algal Siomass. Production and Use, ed. G. Shelef \& C. J. Soeder. Elsevier/North Holland Biomedical Press, Amsterdam, pp. 627-46.

Soeder, C. J. (1980). Massive cultivation of microalgae: results and prospects. Hydrobiologia, 72,197-209.

Stein, J. R. (ed.) (1973). Handbook of Phycological Methods: Culture Methods and Growth Measurements. Cambridge University Press, Cambridge. 
Walne, P. R. (1974). Culture of Bivalve Molluscs. 50 Years' Experience at Conwy. Fishing New Books, Furnham.

Wikfors, G. H. (1986). Altering growth and gross chemical composition of two microalgal molluscan food species by varying nitrate and phosphate. Aquaculture, 59, 1-14. 